\section{Exchange of self-expandable metal stent in endo- scopic ultrasound-guided hepaticogastrostomy}

Endoscopic ultrasound-guided hepaticogastrostomy (EUS-HGS) using a self-expandable metal stent (SEMS) has been reported to be feasible for failed biliary drainage $[1,2]$. However, how to exchange a SEMS after EUS-HGS remains to be established.

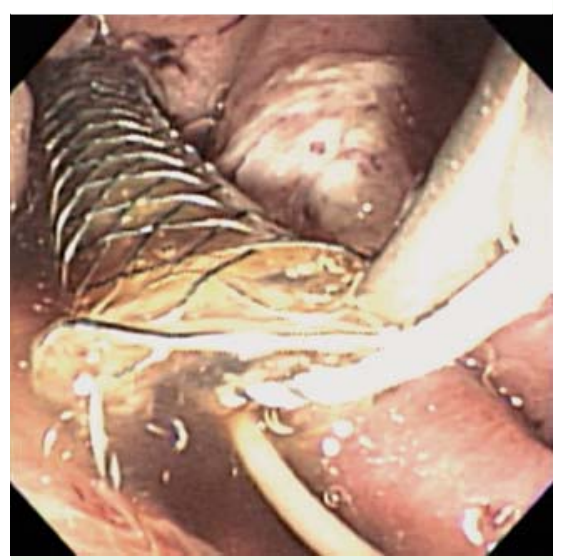

Fig. 1 Endoscopic view showing the retrieval ring of the metal stent grasped by the biopsy forceps beside the guide wire and the endoscopic nasobiliary drainage tube.

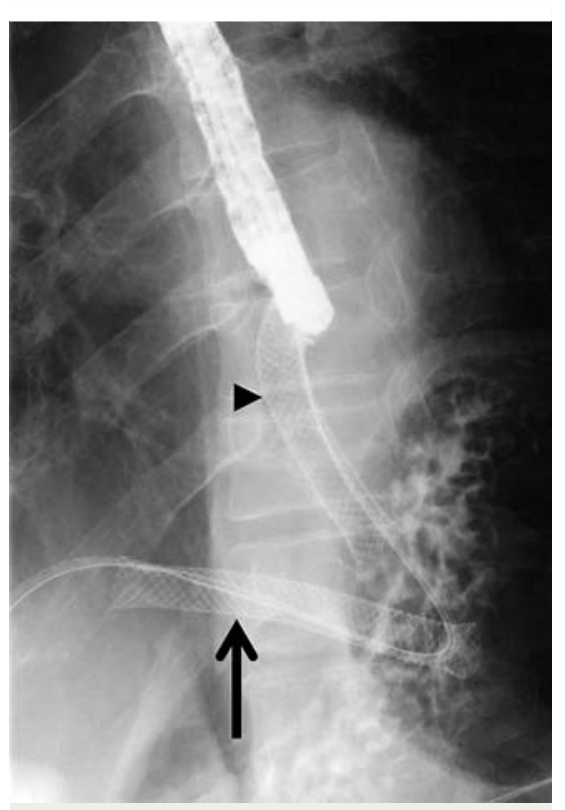

Fig. 2 Fluoroscopic view showing the second metal stent (arrowhead) retrieved together with the duodenoscope. The guide wire and endoscopic nasobiliary drainage tube were kept inside the bile duct through the first metal stent (arrow).
An 80-year-old man with acute cholangitis was referred to our institution. He had a previously placed transpapillary SEMS for ampullary carcinoma. Endoscopic drainage failed because of duodenal obstruction. The patient then underwent EUS-HGS using an 8-cm-long SEMS (fully covered Wallflex; Boston Scientific, Tokyo, Japan). Nine days later, endoscopy revealed that the SEMS had become buried in the gastric wall, so a 6-cm-long SEMS (partially covered Wallflex; Boston Scientific) was additionally placed to prevent complete migration. Seven days after the addition of the second SEMS, an X-ray revealed the SEMS to be distally dislocated toward the stomach.
We planned a SEMS exchange. First, two guide wires were inserted through the SEMS and the papilla into the duodenum, followed by insertion of an endoscopic nasobiliary drainage (ENBD) tube over one of the guide wires using a therapeutic duodenoscope. Next, the retrieval ring of the second-placed SEMS was grasped using a biopsy forceps ( $\bullet$ Fig. 1) and the SEMS retrieved along the guide wire together with the duodenoscope, keeping the guide wire and ENBD tube in place ( Fig.2). As a third step, the duodenoscope was advanced again over the guide wire and the first-placed SEMS was removed in a similar way ( Fig.3). Finally, a 12-cm-long, partially covered SEMS with an uncovered proximal end and a flared distal end, specially designed for use in EUS-HGS (Supremo; Taewoong Medical, Seoul, Korea), was placed ( Fig. 4, Video 1 )

Simple SEMS exchange after EUS-HGS, like transpapillary SEMS [3], is not recom-

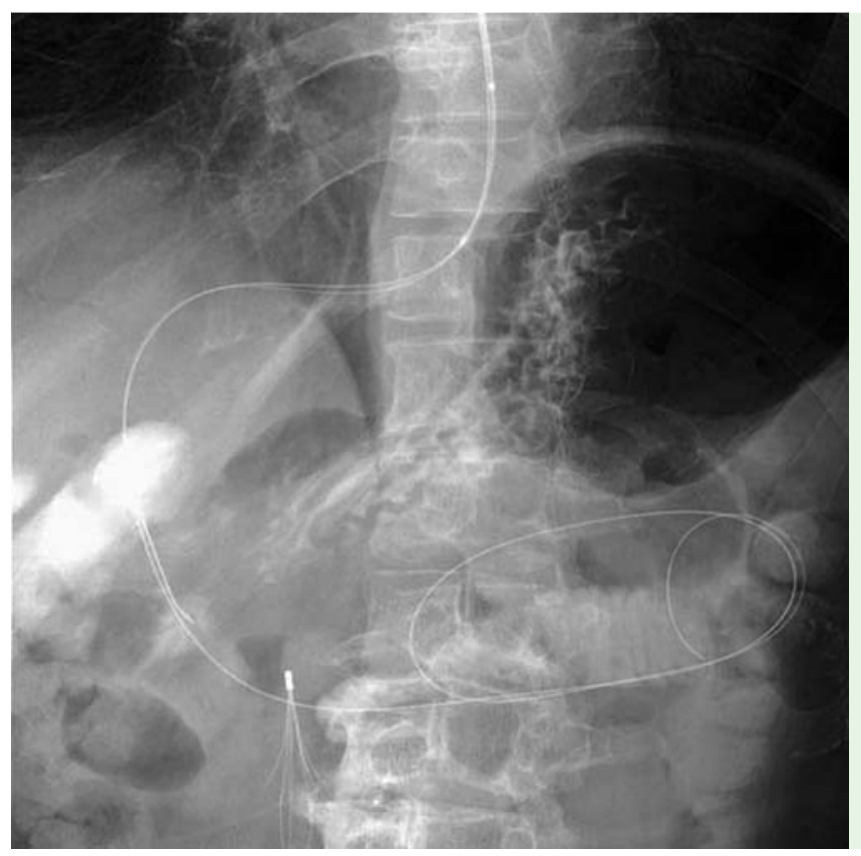

Fig. 3 Fluoroscopic view showing the guide wire and endoscopic nasobiliary drainage tube kept in place through the hepaticogastric fistula.

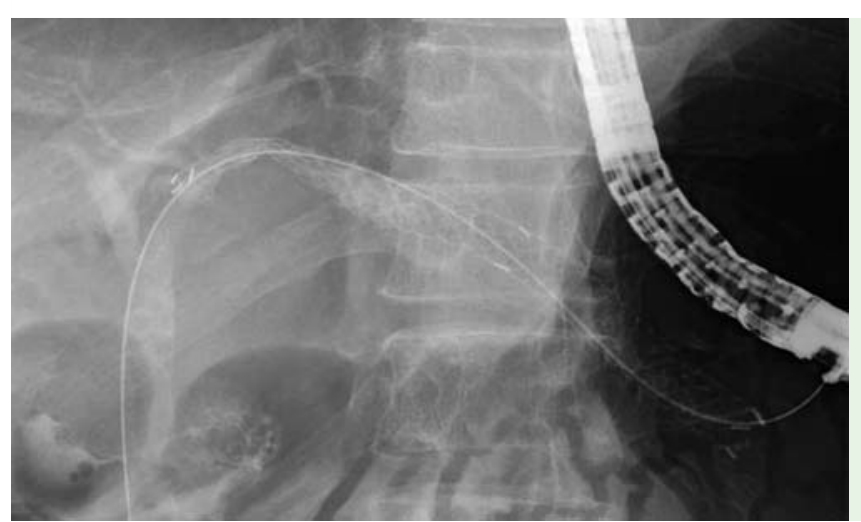

Fig. 4 Fluoroscopic view showing the metal stent placed from the left hepatic duct to the stomach. 
mended because it is difficult to regain access through the hepaticogastric fistula after stent removal. The snare-over-thewire technique has been reported to be useful in plastic stent exchange [4], but is not applicable to SEMS exchange. Although one guide wire is theoretically enough, we used two guide wires with one ENBD tube to ensure against the guide wire slipping out.

\section{Video 1}

First, after the therapeutic duodenoscope was advanced into the stomach, the end of the second Wallflex was grasped by the biopsy forceps and the Wallflex was retrieved along the guide wire together with the duodenoscope. Second, the duodenoscope was advanced over the guide wire and the first Wallflex was retrieved in a similar way. Finally, the duodenoscope was advanced over the guide wire and the new covered metal stent (Supremo) was placed along the guide wire between the left hepatic duct and the stomach.
Endoscopy_UCTN_Code_TTT_1AR_2AZ

Competing interests: None

\section{K. Kawakubo, H. Isayama, H. Kogure, \\ N. Takahara, K. Miyabayashi, \\ S. Mizuno, D. Mohri, T. Sasaki, \\ N. Yamamoto, Y. Nakai, K. Hirano, N. Sasahira, M. Tada, K. Koike \\ Department of Gastroenterology, Graduate School of Medicine, The University of Tokyo, Tokyo, Japan}

\section{References}

1 Savides TJ, Varadarajulu S, Palazzo L et al. EUS 2008 Working Group document: evaluation of EUS-guided hepaticogastrostomy. Gastrointest Endosc 2009; 69: 3-7

2 Park Do H, Song TJ, Eum J et al. EUS-guided hepaticogastrostomy with a fully covered metal stent as the biliary diversion technique for an occluded biliary metal stent after a failed ERCP (with videos). Gastrointest Endosc 2010; 71: 413-419

3 Kasher JA, Corasanti JG, Tarnasky PR et al. A multicenter analysis of safety and outcome of removal of a fully covered self-expandable metal stent during ERCP. Gastrointest Endosc 2011; 73: 1292 -1297

4 Fujita N, Sugawara T, Noda $Y$ et al. Snareover-the-wire technique for safe exchange of a stent following endosonography-guided biliary drainage. Dig Endosc 2009; 21: 48 52

\section{Bibliography}

DOI http://dx.doi.org/

10.1055/s-0032-1309779

Endoscopy 2012; 44: E311-E312

(c) Georg Thieme Verlag KG

Stuttgart · New York

ISSN 0013-726X

\section{Corresponding author}

\section{K. Kawakubo, MD}

Department of Gastroenterology

Graduate School of Medicine

The University of Tokyo

7-3-1 Hongo Bunkyo-ku

Tokyo, 113-8655

Japan

Fax: +81-3-38140021

kkawakubo-gi@umin.ac.jp 